\title{
An Evaluation of the Effectiveness of An Olympism Education Programme to Resolve Conflicts Between Primary School Students in Sri Lanka
}

\section{Samantha Nanayakkara}

Department of Education, University of Peradeniya, Peradeniya, Sri Lanka.samimm2@gmail.com

\begin{abstract}
This paper reports and discusses the findings of an experimental method study that investigated how Olympism education could strengthen competencies on conflict resolution, through delivery of socio-cultural values educating young students in ethnically divided societies in Sri-Lanka. The research examined the initiatives first by investigating the impact of education in promoting peace in Sri Lanka. Secondly, the study provided an explanation for the potential nature of Olympism in conflict resolution and promoting peace in Sri Lanka. The study has introduced an integrated model of Olympism values and conflict resolution strategies and has been tested among primary students who represent the two main Sri Lankan ethnic groups; Singhalese and Tamils. Considering the effects of the intervention, the most notable finding of this study was that conflict resolution and Olympism Education integrated curriculum intervention significantly improved experimental group students' conflict resolution competencies regardless of their gender or ethnicity. This research concluded that strategically designed and carefully managed Olympism lessons can help students to develop and enhance competencies of conflict resolution. In order to achieve significant outcomes in young children's ability to learn to resolve their conflicts when they were exposed to physical education lessons, it is needed to employ experiential learning opportunities through a well balanced theoretical basement and sporting activities.
\end{abstract}

Keywords: Conflict resolution, ethnic animosity, experiential learning, fragile societies, Olympism, physical education, socio cultural values

\section{Introduction}

Fragile societies of brutal conflicts require possible ways to reconstruct their peaceful societies. In order to maintain the future generation away from ferocious and deplorable situations, it is necessary to provide vigilant protection to them. Particularly, children who have been directly affected by a conflict 
as victims of violence need post-conflict assistance to meet the challenges of reconstruction. How could children in a fragile society get involve in their postconflict reconstruction process? Why it is important to provide appropriate educational responses to children for preventing conflict and reconstructing post-conflict societies? Without a critical and thorough understanding of the complex context in the long term conflict, children could end up with a set of irrelevant or even undesired attitudes and skills (Hart, 2004). The challenge for governments and civil society is to channel the energy, ideas and experience of youth and children into contributing positively towards the creation of more peaceful societies (United Nations, 2006). Education plays a key role in conflict resolution situations and Nicolai and Triplehern (2003) claim that education programs support children's psychological and social well being by re-establishing normal routines and peer network. Education has the capacity to offer "an adaptive response, addressing some of the particular conditions that arise from conflicts" (Nicolai \& Triplehern, 2003, p. 20).

Sri Lanka is a nation that is divided by an ethnic conflict that spanned for almost three decades. The origin of the conflict can be attributed to postindependent political decisions and education and language policies which polarized ethnic relations between the two major communities Sinhalese and Tamils (Bandarage, 2008), and this had a major impact on Sri Lanka's politics, economy, society, and education system (Lopes-Cardozo, 2009). As the conflict escalated Sri-Lanka's ethnic division became worse. The effect on children, in particular, caused emotional trauma, social rejection and even physical abuse. Children were recruited to the battle-front without the consent of parents and recruitment of child soldiers for separatists' activities continued despite international protests (UNICEF, 2001). The fear of their children being forced into action by the Liberation Tamil Tiger Elam (LTTE) stopped parents from sending their children to schools and therefore, many schools were unable to function (UNICEF, 2001). In addition, many victimized children were living in refugee camps as internally displaced people and this further interrupted the schooling process. Some schools in the war-affected area were taken over for government sponsored rehabilitation camps and children were deprived of education over many years (Ministry of Education, Sri Lanka (MOESL), 2002). Therefore, it is questionable whether Sri Lankan primary school students will have the opportunities to explore the relationship between various areas of conflicts which they are daily confronted within different environments, and how their own attitudes could influence negatively or positively to resolving conflicts through their first hand experiences. Religions are directly affected by the ethnic conflict in Sri Lanka; therefore, integration among ethnic groups seems only apparent within the same religious group. Nevertheless, all religions spread harmonious values; yet integration through religion is rarely achieved in Sri Lanka. People in Sri Lanka have faced the ethnic conflict for three decades and at present, they need to develop ways 
to help people avoid future conflicts. In particular, they need to be able to manage a conflict through their own experiences.

The purpose of this study is to investigate whether Sri Lankan primary school students' knowledge and skills of conflict resolution could be constructed by means of student centered learning in Olympism. Hence, it is open to debate whether the implementation of an Olympism education and conflict resolution integrated curriculum model could make a difference to the students' conflict resolution competencies. This study bears significant practical and sociological relevance to educational research. Therefore, the findings aimed to provide implications for researchers, teachers and administrators.

\section{Background}

There is evidence to suggest that sport can have a positive impact on relationships between members of antagonistic groups in divided societies (Norman, 2009). Highlighting the educational value of sport, Kidd and MacDonell (2007) emphasise that sport is a positive tool for the promotion of goals such as unity, peace and education. Kidd (2008) further emphasises how sport and physical activity can be used for reconciliation and intercultural communication in areas of conflict. United Nations (2006) endorses that sport builds bridges between individuals and cross communities.

Olympism is a social philosophy which emphasises the role of sport in world development, international understanding, peaceful co-existence, and social and moral education (Parry, 2003). One of the main objectives of the Olympism is educating individuals and teaching them to adapt to their living conditions (Lassoued, 1997). Diem (1986) expressed that the educational value of Olympism as the Olympic idea is not confined to Olympic events or to the Olympic Games; it comprises a sum of moral behavioral patterns to govern one's life. Also, Diem (1986) emphasises that by spreading the educational values of Olympism, societies are capable of raising humanity among individuals. Chapter IV in the IOC Charter (IOC, 2010) explains the National Olympic Committee's duties in relation to promote culture and education.

The meaning of the term 'Olympic education' appears in the pedagogy of sport and in Olympic research after 1970 (Muller, 2004). Olympic education, "as a means for the cultivation of ethical values, is perceived as a multidimensional educational tool aimed at exercising influence in all dimensions of human nature" (Kamberidou, 2008, p. 49). Patsantaras (2008) emphasises that Olympic education appears today as an educational model which pursues the harmonization of the elements of human nature. 
However, Culpan and Wigmore (2010) introduce a new term 'Olympism education' rather than the traditional term 'Olympic education'. According to Culpan and Wigmore (2010) Olympic education tends to focus on the Olympic Games while Olympism education focuses on the perspectives of the concept of Olympism. Culpan and Wigmore (2010) argue there is a need for Olympism education to change current Olympic education practice. Culpan and Moon (2009) defined Olympism education as "a culturally and critically relevant, experiential process of learning an integrated set of life principles through the practice of sport" (p. 17). This definition affirms the IOC's definition that Olympism is blended with culture and sport. I define Olympism education as a process of holistic human development in post modern society; that nourishes ethical behaviour through sport, strives to excel in the spirit of fairness and flourishes humanitarianism.

\section{Olympism education praxis}

Some countries have identified the importance of Olympism within the schooling context whether through physical education or cross curricula approaches. Among them, the New Zealand school curriculum has undergone a major review over the last decade. Culpan (2001) emphasises that in New Zealand, the state encouraged the teaching of attitudes and values in physical education, and that those attitudes and values promoted in the curriculum are consistent with Olympism. The inclusion of Olympism into physical education programme has encouraged the development of critical thought around the institutionalisation of sport in general and Olympic Movement in particular.

Kabitsis, Harahousou, Avanti and Mountakis (2002) conducted a study on implementing Olympic culture in the school curriculum in Greece. A total of 392 boys and 393 girls from 6th grade of 32 Greek schools participated in this study. By means of a questionnaire, the study used a pre-test and post-test format covering three areas: the improvement on the participant's knowledge about some basic concepts of the Olympic Games; the benefits of exercise and the student's sportsmanship and attitudes towards fair play. It is reported that the implementation of Olympic culture in the school curriculum in Greece had a beneficial effect. The outcome of the study was that students' knowledge of the Olympic Games was greatly improved their attitudes towards the benefits of exercise and their level of sportspersonship were also positively affected.

Ha, (2004) examined the effects of different teaching approaches of values based Olympic education programs on primary students from selected schools in Hong Kong. Six hundred and sixteen primary grades 5-6 students were assessed using pre and post-tests. Areas covered by these tests included moral judgment, moral reason, moral intention and pro-social behaviour. The 
outcome of this study has indicated that the students' Olympism knowledge and a certain degree of moral behaviour was judged by their teachers to have improved highly after participating in a twelve-week value based program.

Bronikowski (2006) carried out a three-year experimental research on achievement in teaching Olympism in Polish schools. This intervention program was introduced to the 13 year old pupils in Poznan, Poland in the year 2000. In this research 230 boys and 220 girls took part and among them, 106 boys and 100 girls completed the pre and post-tests. The change of Olympic awareness of school children was mainly observed. After a three year project based on Olympic education; post-test examination results revealed that $75 \%$ of boys believed in the pursuit of excellence promote Olympism in compared to $87 \%$ of girls. Boys showed $60 \%$ in fair play and peaceful youth meeting during Olympic contests. In parallel $86 \%$ of girls believed in fair play. More girls associated with personality development $(65 \%)$ and body and mind development (80\%) with the Olympic movement.

\section{Conflict resolution praxis}

Conflict resolution (CR) is "a constructive approach to interpersonal and intergroup conflicts that helps people with opposing positions work together to arrive at mutually acceptable compromised solutions" (Morton, 1991, p. 1). Encarnacion, McCartney, and Rosas (1990) emphasise that there is a need to build constituencies and capacity within societies and to learn from domestic cultures how to manage conflicts over time in a sustained manner. Lederach (1997) emphasises that peace building centrally involves the transformation of relationships and "sustainable reconciliation requires both structural and relational transformation" (p, 82). Peace education includes "conflict resolution, antiracism, multiculturalism, cross-cultural training and the cultivation of a generally peaceful outlook" (Soloman, 2002, p. 7).

Recent years have witnessed an increasing number of studies related to conflict resolution (CR) in schools for the purpose of creating a more peaceful society. A study by Heydenberk and Heydenberk (2005), titled 'Increasing Meta-cognitive Competence through Conflict Resolution' aimed to determine the effects of conflict resolution and related social skill development on student's meta-cognitive competencies. The study involved fourth and fifth grade students from elementary schools in the Philadelphia school district and a neighbouring urban school district. Ten experimental and eight comparison groups were assessed for differences in pre and post-tests using 'one-tailed t test' with 'alpha levels' of 0.05 . The results suggest that the students in the treatment groups demonstrated significant improvement in meta-cognitive skills such as cooperativeness, moral and ethical reasoning, emotional 
awareness, communication skills, critical thinking and comprehension. The research outcome highlights the importance of integrating conflict resolution and social skill training into curricula.

Bilgin (2008) examined the impact of conflict resolution training on elementary school children, and concluded that students should be taught to cope with conflicts through constructive strategies, because low academic achievement, low self esteem, stress and violence are the results of destructive conflict resolution. The study was carried out with 217 fourth grade students randomly assigned to experimental $(\mathrm{N}=14)$ and control groups $(\mathrm{N}=14)$. Both groups were asked the "most common conflicts they had experienced" and the most frequent responses were written as two scenarios. These were given as a pre-test to the students who were asked to resolve these conflicts. Kendall's Coefficient of concordance was used to rate the number of responses of conflict strategies theory and their reliability. The experimental group received 10 hours of training over 30 minutes twice a week. The control group was given no training. The same questionnaire was delivered in terms of a posttest. The results of the pre and post-tests were evaluated. Results indicated no significant difference between the pre and the post-test.

\section{Method}

The overarching aim of this study was to examine the effectiveness of implementing Olympism education lessons in Sri Lankan state primary schools with the purpose of increasing children's knowledge of resolving conflicts in order to achieve peace.

Based on the above mentioned aim, the following specific research question was formulated:

Can Sri Lankan primary students apply their knowledge of Olympism to resolve conflicts?

In order to answer the research question, the experimental method was approached in this study. The rationale for selecting experimental method approach for this study was to encompass statistical analysis by using pre and post-tests. Ethical approval for the study was obtained from the relevant authorities.

\section{Study sample}

Two primary schools out of 98 schools in the Kandy district were selected randomly from the list of schools of the Central Province Ministry of Education, Sri Lanka. Four groups of year 5 students (10-11 years old) 
totalling 84 students from the two primary schools (further called A \& B) were selected for comparison in this study. The predominant ethnicity of School A was Singhalese / Buddhist, and School B was Tamil / Hindu and both were mixed (girls and boys) schools. Two groups (A \& B) of primary students consisting of 41 students (with 17 girls and 24 boys), 21 from the School A and 20 students from School B were randomly selected as the experimental (intervention) group. The remaining two groups consisted of 43 students (with 18 girls and 25 boys), 21 from the School A and 22 students from School B, and were defined as the comparison group.

\section{Procedure}

There is a period of 40 minutes in the state primary school timetable each week in Sri Lanka to practice core curricular activities. During this period, the experimental groups received instructions on Olympism education and conflict resolution lesson units for a total of 19.00 hours over 28 weeks. Students of the control groups did not receive any conflict resolution (CR) and Olympism education $(\mathrm{OE})$ intervention but they involved in their normal core curricular activities. Each school year five class teacher and their physical education teacher engaged in team teaching. Rationale for the team teaching was while Sri Lankan physical education teachers were not trained in primary teaching, year five class teachers were fully trained in primary teaching. However, year five class teachers were not competent in Olympism teaching. Use of combined knowledge and experience of both teachers by team teaching was taken in to consideration to avoid the proficiency bias. Before implementing the intervention, all teachers from both schools participated in four teacher training workshops. The intention for the teacher training workshops in this study was to introduce the teachers how to teach integrated Olympism education and conflict resolution strategies with sporting activities effectively. The main teacher training workshop for concepts of Olympism and conflict resolution was held as a five days residential workshop, integrated with the 2009 annual National Olympic Academy (NOA) with the collaboration of the National Olympic Committee (NOC) of Sri Lanka. Additional three workshops (one day each) were conducted related to teaching-learning methods (cooperative learning, problem based learning and experiential learning) in primary teaching and physical education. All these workshops were conducted by lecturers in teacher education and National Olympic Committee resource persons in Sri Lanka.

At the beginning of this intervention process, I clearly stated that the research participants' (students) feelings and thoughts will be respected in this study. It was also explained that as an outsider, I would act as an 'initiator', 'implementer' and 'observer' in this research and it was necessary to avoid utilising my personal values, beliefs and judgments. The whole process of 
this study was responsive and everyone was expected to consider each other's situation, feelings and thoughts. The participants and I agreed to work as a team throughout the intervention process by sharing knowledge, problems, questions, solutions, values, beliefs, and responsibilities.

A series of Olympism and conflict resolution concepts were integrated as a special curriculum model in this study. This integrated curriculum model was followed by the students during the intervention of this study. Each theme in the integrated curriculum model had classroom activities for conflict resolution lessons and outdoor sporting activities for Olympism lessons. The focus of the integrated curriculum lessons by introducing CR strategies through Olympism values were combined with Sri Lankan values to reinforce the students' cultural pride. For instance, when talking about tolerance as an Olympic value associated with CR, it was important to highlight how tolerance is addressed as a value of Sinhalese, Tamil and Muslim and other cultures in Sri Lanka.

The following section discusses the Olympism education and conflict resolution integrated curriculum model.

\section{The Olympism education and conflict resolution (OE \& CR) integrated curriculum model}

Binder (2001) identified two different directions in School Based Olympic education; first, pure curriculum based on the theory of Olympism as articulated by Coubertin and others learning focused on the integration of Olympic themes. Second, the topics of Olympics with content and process of objectives address in existing educational curricula. In the OE \& CR integrated curriculum model of this study, lessons were planned to focus on and build around Olympism values, integrated with conflict resolution core elements, mainly understanding each person's point of view in conflict situations. Naul (2008) introduced two instructive approaches as objectives for teaching Olympic education: a 'knowledge-oriented' approach (the historical and educational legacy of Olympic idea) and an 'experience-oriented' approach (the Olympic experience having from both inside and outside the school) (p.118). Therefore, both of above mentioned approaches were employed in the OE and CR integrated curriculum model.

It was considered that constructivism needed to be practiced in standard $\mathrm{OE}$ and CR integrated model teaching-learning practice. Critical constructivists believe that students' engagement in the knowledge production process at schools is more important than transmitting knowledge through memorization (Taylor, 1998). According to Kincheloe (2005) the knowledge of the classroom is constructed where students' personal experiences interact with academic knowledge. Thus, during the learning of $\mathrm{CR}$ and $\mathrm{OE}$ integrated 
curriculum model, students were asked to construct new meanings based on their prior knowledge, understanding and experiences. They were provided with classroom opportunities to experiment, examine models, and reflect and decide on functional patterns that satisfied their personal conflict resolution knowledge and skills.

Themes in the OE \& CR integrated curriculum model focused on critical thinking skills (critical literacy) related to Olympism and conflict resolution associated to practical sporting activities. Bailin et al., (1999) suggested critical thinking instructions that include: value reason and truth, respect others during discussions, be open-minded and empathetic, perceive differences between definitions and empirical statements, use cognitive strategies and consider alternatives before decision making are suitable for teaching students at the primary grade level. Consequently, the teaching-learning process of the intervention in this study implemented these instructions.

The lessons of this OE and CR model were carried out as student-centered activities to give them first-hand experiences. Students were asked to find the relationship between areas of conflict which they were confronted with daily in different environments, and how their own attitudes could influence conflict resolution negatively or positively (conflict resolution literacy). Practical sporting activities associated with these integrated lessons were comprised with basic skills of Basketball, Netball, Football and Cricket. Mixed cultural groups of students (previously mentioned) participated in above sports with enhanced critical thinking on Olympism values i.e. why, how and when to tolerate while playing, how to play fairly, how to respect for multiculturalism while playing (social literacy). This part of the model led students to develop their self-discipline and motivation for positive conflict resolution during sporting activity.

The significance of this CR and OE integrated curriculum model is it has developed a pristine idea on Olympism and physical education, emphasizing its potentiality of conflict resolution and peaceful living in a multicultural society. Therefore, the outcome of this model has released a novel concept to the rest of the curriculum studies. The OE and CR integrated curriculum model was intended to impart a broad understanding of critical literacy.

This study was planned with a focus of developing a programme as an intervention and data was collected from students about their perspectives of conflict resolution by use of a questionnaire before and after the intervention. The Ohio Conflict Resolution basic Knowledge Test for Grades 3-5 comprised of 14 conflict resolution questions and the Cronbach alpha coefficient reliability for this instrument was recorded at 0.90. As the level of Cronbach alpha coefficient reliability is acceptable, it was decided to 
use the test guidelines of the Ohio Commission on Dispute Resolution and Conflict Management as a measurement in this research. This questionnaire was translated in to Sinhalese and Tamil languages by two professional Sri Lankan translators and a pilot test was carried out within two Sinhalese and Tamil primary schools in the same area (Kandy) in Sri Lanka. Pilot test results revealed that primary students from both schools were able to understand and answer the questionnaire and the Cronbach alpha coefficient reliability for this instrument was recorded at 0.70. Therefore, The Ohio Conflict Resolution Basic Knowledge Test for Grades 3-5 (CR test) was administered in both pre and post intervention phases in this study. All students were assessed at the same time at each school to avoid any time that might influence students' performances.

Independent sample t-tests were carried out to evaluate the group differences of pre-tests within the same school of the performances of the students' conflict resolution competencies. Mann Whitney $\mathrm{U}$ tests were carried out to evaluate the post-test group differences within and between schools. This test was selected for analysing the post-test data as the distribution of the posttest data did not follow a normal distribution, one of the basic assumptions necessary for using the t-test. Data were analysed by Univariate Analysis of Variances and Co-variances (ANOVA and ANCOVA) by using the computer programme Software for Package for Social Sciences (SPSS) 17.0 version. Effect sizes for all statistically significant differences were calculated by utilising the effect size index Cohen's $d$ with the conventional values of small $d=0.1$, medium $d=0.3$ and large $d=0.5$. An Alpha level of .05 was used for all statistical analysis (Portney \& Watkins, 2000).

These analyses were intended to investigate the effectiveness of the intervention in students' competencies that are particularly relevant to conflict resolution. The three areas of CR questionnaire; CR attitudes, CR knowledge and assertiveness and cooperativeness of $\mathrm{CR}$, served as the dependant variables. Consequently, group served as the predictor variable in this study. As this study's data was acquired from two schools (A \& B) test results comparisons of experimental and control groups were made separately within and between two schools.

\section{Results}

In order to determine whether students' conflict resolution competencies differ within different schooling contexts, it was hypothesised that there will be a difference of CR competencies between groups before and after the intervention. Results obtained from the analysis of scores on the CR questionnaire (pre-test) is summarised in table 1 below. 
Table 01: Pre-test group comparison of conflict resolution competencies

\begin{tabular}{|c|c|c|c|c|c|c|c|c|c|c|}
\hline \multirow[t]{2}{*}{ Pre-test } & \multirow[t]{2}{*}{ School } & \multicolumn{2}{|c|}{$\begin{array}{l}\text { Experimental } \\
\text { group }\end{array}$} & \multicolumn{2}{|c|}{$\begin{array}{l}\text { Control } \\
\text { group }\end{array}$} & \multirow[t]{2}{*}{$\mathrm{t}$} & \multirow[t]{2}{*}{$\mathrm{df}$} & \multirow[t]{2}{*}{$\mathrm{d}$} & \multirow[t]{2}{*}{$\mathrm{r}$} & \multirow[t]{2}{*}{ p-value } \\
\hline & & M & $\mathrm{SD}$ & M & $\mathrm{SD}$ & & & & & \\
\hline \multirow{2}{*}{$\begin{array}{l}\text { Positive } \\
\text { attitudes }\end{array}$} & A & 2.62 & 0.51 & 2.46 & 0.36 & 1.191 & 40 & 0.376 & 0.185 & 0.241 \\
\hline & B & 2.61 & 0.55 & 2.53 & 0.58 & 0.475 & 40 & 0.15 & 0.074 & 0.638 \\
\hline \multirow{2}{*}{$\begin{array}{l}\text { Negative } \\
\text { attitudes }\end{array}$} & A & 2.67 & 1.02 & 2.9 & 0.94 & -0.787 & 40 & 0.248 & 0.123 & 0.436 \\
\hline & B & 2.7 & 1.09 & 2.68 & 1.04 & 0.056 & 40 & 0.017 & 0.008 & 0.956 \\
\hline \multirow{2}{*}{$\begin{array}{l}\text { Positive } \\
\text { knowledge }\end{array}$} & A & 2.21 & 0.41 & 2.41 & 0.37 & -1.714 & 40 & 0.542 & 0.261 & 0.094 \\
\hline & B & 2.46 & 0.51 & 2.45 & 0.39 & 0.027 & 40 & 0.008 & 0.004 & 0.978 \\
\hline \multirow{2}{*}{$\begin{array}{l}\text { Negative } \\
\text { knowledge }\end{array}$} & A & 2.7 & 0.73 & 2.64 & 0.57 & 0.235 & 40 & 0.074 & 0.037 & 0.816 \\
\hline & B & 2.87 & 0.72 & 2.77 & 0.59 & 0.503 & 40 & 0.159 & 0.079 & 0.617 \\
\hline \multirow{2}{*}{ Assertiveness } & A & 2.68 & 0.61 & 2.73 & 0.44 & 0.29 & 40 & 0.091 & 0.045 & 0.774 \\
\hline & $\mathrm{B}$ & 2.82 & 0.48 & 2.74 & 0.48 & 0.501 & 40 & 0.158 & 0.078 & 0.619 \\
\hline \multirow{2}{*}{ Cooperativeness } & A & 2.4 & 0.25 & 2.43 & 0.28 & 0.473 & 40 & 0.149 & 0.074 & 0.639 \\
\hline & $\mathrm{B}$ & 2.53 & 0.3 & 2.49 & 0.31 & 0.424 & 40 & 0.134 & 0.066 & 0.674 \\
\hline
\end{tabular}

The pre-test scores revealed that both the experimental and control groups of School A and B demonstrated equal competencies showing positive and negative attitudes towards CR. However, results indicated that in both School A and B students' negative attitudes towards CR were relatively higher than positive $\mathrm{CR}$ attitudes. The pre-test results further revealed that there were no significant differences in the positive and negative knowledge of CR between the experimental and control groups within the two different schools. However, results demonstrated that in both Schools A and B students' negative knowledge of $\mathrm{CR}$ reached almost higher than the positive knowledge of CR. The next part of the pre-test analysis examined the competencies of assertiveness and cooperativeness in CR among students. These results also revealed that there was no significant difference between acquiring competencies that included assertiveness and cooperativeness in CR between the groups of School A and B. However, results demonstrated that both School A and B student competencies of assertiveness demonstrated almost higher than the competencies of cooperativeness in CR. Therefore, the null hypothesis of 'there would be no significant difference between groups in pretest CR competencies within School A and B' was accepted.

Results obtained from the analysis of scores on the CR questionnaire (posttest) is summarised in table 2 below. 
Table 02: Post-test group comparison of conflict resolution competencies

\begin{tabular}{|c|c|c|c|c|c|c|c|c|c|}
\hline \multirow{2}{*}{ Post-test } & \multirow{2}{*}{ School } & \multicolumn{2}{|c|}{$\begin{array}{l}\text { Experimental } \\
\text { group }\end{array}$} & \multicolumn{2}{|c|}{$\begin{array}{l}\text { Control } \\
\text { group }\end{array}$} & \multirow{2}{*}{$\mathrm{u}$} & \multirow{2}{*}{$\mathrm{z}$} & \multirow{2}{*}{$\mathrm{r}$} & \multirow{2}{*}{$\mathrm{p}$-value } \\
\hline & & $\begin{array}{c}\text { Mean } \\
\text { rank }\end{array}$ & $\begin{array}{l}\text { Sum of } \\
\text { ranks }\end{array}$ & $\begin{array}{c}\text { Mean } \\
\text { rank }\end{array}$ & $\begin{array}{l}\text { Sum of } \\
\text { ranks }\end{array}$ & & & & \\
\hline \multirow{2}{*}{$\begin{array}{l}\text { Positive } \\
\text { attitudes }\end{array}$} & A & 32 & 672 & 11 & 231 & 0 & 5.655 & 0.617 & 0 \\
\hline & B & 32.45 & 649 & 11.55 & 254 & 1 & 5.588 & 0.61 & 0 \\
\hline \multirow{2}{*}{$\begin{array}{l}\text { Negative } \\
\text { attitudes }\end{array}$} & A & 12 & 252 & 31 & 651 & 21 & 5.533 & 0.604 & 0 \\
\hline & B & 12.5 & 250 & 29.68 & 653 & 40 & 5.058 & 0.552 & 0 \\
\hline \multirow{2}{*}{$\begin{array}{l}\text { Positive } \\
\text { knowledge }\end{array}$} & A & 30.12 & 632.5 & 12.88 & 270.5 & 39.5 & 4.613 & 0.503 & 0 \\
\hline & B & 31.83 & 636.5 & 12.11 & 266.5 & 13.5 & 5.316 & 0.58 & 0 \\
\hline \multirow{2}{*}{$\begin{array}{l}\text { Negative } \\
\text { knowledge }\end{array}$} & A & 12.07 & 253.5 & 30.93 & 649.5 & 22.5 & 5.394 & 0.589 & 0 \\
\hline & B & 11.05 & 221 & 31 & 682 & 11 & 5.607 & 0.612 & 0 \\
\hline \multirow{2}{*}{ Assertiveness } & A & 11 & 231 & 32 & 672 & 0 & 5.883 & 0.642 & 0 \\
\hline & B & 10.5 & 210 & 31.5 & 693 & 0 & 5.834 & 0.637 & 0 \\
\hline \multirow{2}{*}{ Cooperativeness } & A & 32 & 672 & 11 & 231 & 0 & 5.587 & 0.61 & 0 \\
\hline & B & 32.5 & 650 & 11.5 & 253 & 0 & 5.576 & 0.608 & 0 \\
\hline
\end{tabular}

The post-test analysis indicated that there was a significant difference in posttest scores between the experimental and control groups within School A and B separately on attitudes, knowledge and, assertiveness and cooperativeness in CR. Therefore, the null hypothesis of "there would be no significant difference in post-test CR competencies between groups within School A and B" was rejected.

\section{Group comparison for pre and post-test conflict resolution competencies between schools $A$ and $B$}

Results obtained from the analysis of scores on the CR questionnaire (pre and post-tests) between schools A and B are summarised in table 3 below.

Table 03: Group comparison for Pre and Post-test conflict resolution competencies between schools A and B

\begin{tabular}{lll}
\hline $\begin{array}{l}\text { Categories of the conflict } \\
\text { resolution questionnaire }\end{array}$ & \multicolumn{1}{c}{ Pre- test } & Post- test \\
\hline $\begin{array}{l}\text { Negative attitudes } \\
\text { Positive attitudes }\end{array}$ & $\mathrm{F}=.328, \mathrm{df}=1,76 ; \mathrm{p}=.569$ & $\mathrm{~F}=.000 \mathrm{df}=1,76 ; \mathrm{p}=.987$ \\
Positive knowledge & $\mathrm{F}=.938, \mathrm{df}=1,76 ; \mathrm{p}=.336$ & $\mathrm{~F}=.092, \mathrm{df}=1,76 ; \mathrm{p}=.762$ \\
Negative knowledge & $\mathrm{F}=.222, \mathrm{df}=1,76 ; \mathrm{p}=.639$ & $\mathrm{~F}=.121, \mathrm{df}=1,76 ; \mathrm{p}=.729$ \\
Assertiveness & $\mathrm{F}=.002, \mathrm{df}=1,76 ; \mathrm{p}=.967$ & $\mathrm{~F}=.124, \mathrm{df}=1,76 ; \mathrm{p}=.726$ \\
Cooperativeness & $\mathrm{F}=.004, \mathrm{df}=1,76 ; \mathrm{p}=.951$ & $\mathrm{~F}=.321, \mathrm{df}=1,76 ; \mathrm{p}=.573$ \\
\hline
\end{tabular}


Results from the ANOVA demonstrated that there was no significant difference between all the groups of School A and B with regard to the competencies of knowledge and attitudes of conflict resolution and competencies of assertiveness and cooperativeness of conflict resolution during the pre-test. Therefore, the null hypothesis of 'there would be no significant difference in pre-test CR competencies between groups of School A and B' was accepted.

Results from the ANCOVA demonstrated that there was no significant difference between experimental groups of School A and B and between the control groups of School A and B with regard to the competencies of knowledge, attitudes, assertiveness and cooperativeness of conflict resolution during the post-test. Figure 01 below demonstrates the assertiveness competencies compared between schools A and B groups after the intervention.

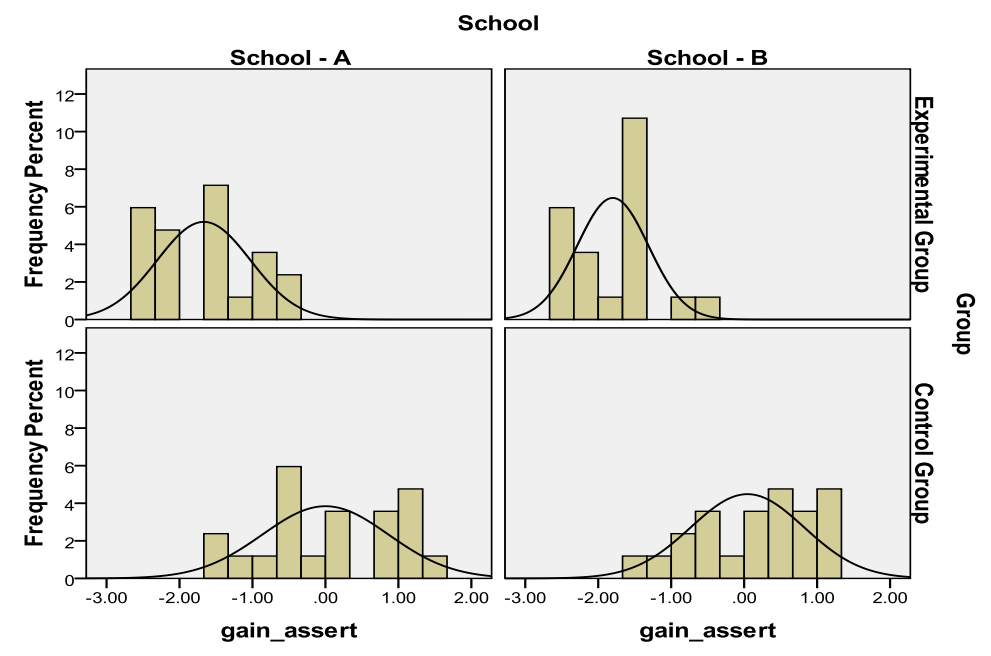

Figure 01: Groups' assertiveness compared between schools A and B after the intervention

Therefore, the null hypothesis of "there would be no significant difference in CR competencies between groups in School A and B after the intervention" was accepted.

\section{Discussion}

The purpose of this study was to examine the effectiveness of implemented Olympism education lessons in Sri Lankan state primary schools with the purpose of increasing children's knowledge of resolving conflicts in order to achieve peace. The pre-test findings revealed that there were no significant differences in the positive and negative knowledge of CR between the experimental and control groups within the two different schools. However, 
in both Schools A and B, students' negative knowledge of CR reached almost higher than the positive knowledge of CR. This equal positive and negative knowledge between the two groups may be related to the variable experiences and habits of their cultures and communities. This finding is consistent with the argument of Ramsbotham, Woodhouse and Miall's (2005) who suggest that the way we deal with conflict is a matter of habit and choice, and furthermore, that it is possible to change habitual responses and exercise intelligent choices. Thus, it was found that a significant deficit existed in current programmes organised to implement CR knowledge for the Sri Lankan primary students. These should therefore be noted and reinforced to emphasise the importance of effective interventions and training to reduce conflict.

The study found that both School A and B student competencies of assertiveness demonstrated almost higher than the competencies of cooperativeness in CR. This is an interesting finding about displaying similar competencies of assertiveness and cooperativeness among the two distinct ethnic groups. This was probably because of the violence of ethnic conflict in their society may have resulted in both ethnicities of students having experienced aggressive situations in their lives. This finding supports Garca's (2001) conclusions that in conflict areas children are deliberately exposed to horrific scenes in order to harden them to violence. Some are forced to commit atrocities against their own families as a way of severing ties with their communities. This study finding also supports Garbarino, Dubrow, Kostelny and Pardo's (1992) finding that the cycle of violence can become perpetual in areas affected by higher levels of community violence. Reaffirming this finding Huesmann (1986) emphasises that when children are continually exposed to aggression and violence, whether in the neighbourhood, at school, at home or on television, children begin to model it. This study suggests that in order to reach the goal of reducing conflict in both Sri Lankan Schools, students require more knowledge of and training in skills for cooperativeness.

The major finding in this study was that after participating in the CR and OE intervention, experimental group students placed a positive competency transformation in conflict resolution. This study's post-test results support the hypothesis that the experimental group students receiving Olympism education lessons would be able to resolve conflicts effectively following the intervention and rejected the null hypothesis. The post-test data in this study revealed that the $\mathrm{OE}$ and $\mathrm{CR}$ intervention lessons were effective in teaching students how to resolve conflicts. This result supports Johnson \& Johnson's (2005) study which has also shown that various types of CR training can be integrated with different curricula and concluded that direct instructions in $\mathrm{CR}$ are effective. It is also found that CR skills which have been organised to serve group environments in this study have successfully helped students to interact with their peers. In his study, Edleson (1981) revealed that when 
students' expose to group experiences in present situations are more applicable to the real world, they were able to gain successful conflict resolution skills. Consistent with prior research (pre-test), the analyses of the post-test results demonstrated significant differences between the experimental and control groups on CR competencies. Students of experimental groups of both Schools $\mathrm{A}$ and $\mathrm{B}$ performed significantly better on CR positive attitudes, positive knowledge and cooperativeness than students of the control groups in both Schools A and B after the intervention. Therefore, this study suggests that the success of those lessons conducted in $\mathrm{CR}$ and $\mathrm{OE}$ integrated model increases the experimental student groups' positive knowledge, attitudes about CR and skills in conflict resolution by promoting less assertiveness but more cooperativeness.

When considering overall findings of the post-test analyses for the existence of group differences in competencies acquired in CR between Schools A and $\mathrm{B}$ after the intervention, the Univariate Analysis of Variance revealed the existence of a significant difference between experimental and control groups in both Schools for their attitudes, knowledge and skills (assertiveness and cooperativeness) in CR. In respect to the total scores, it is evident that experimental groups in both Schools demonstrated significantly higher than their control groups for the positive attitudes, knowledge and cooperativeness developed in CR. In contrast, negative attitudes, knowledge and assertiveness to $\mathrm{CR}$ in both Schools' experimental groups were significantly lower than control groups.

The explanation of these results may be associated with a number of factors. First, it may be the high effectiveness of the implemented CR and OE integrated curriculum model. This model was created as experiential learning and designed with practical based activities. Particularly, concepts of Olympism activities based on team sports were carried out in the playground and group activities on conflict resolution were mostly carried out in the classroom. Second, it may be that the students' activities were useful, understandable and applicable for them. Finally, it may also have impacted on the effectiveness of teaching-learning process for students' achievements. Teachers who were involved in teaching this curriculum were trained on the subject knowledge and teaching methods and printed materials regarding teaching instructions were also supplied. Naul (2008) introduced knowledge oriented and experience oriented approaches for teaching Olympism and both approaches were applied at the intervention. This may have impacted on successful learning in Olympism. This is supported by Honig's (1982) finding that use of games format lessons, pictured distress, dioramas and behaviour incidents evoked children's empathy and sympathy, and helped them to learn how to share, help and comfort others. Reaffirming this finding Breunlin, Cimmarusti, Bryant-Edwards, and Hetherington (2002) emphasise that violent behaviour 
is learned and can be prevented through teaching alternate behaviours. The above statement can be supported from this study in terms of evidence found that experimental groups of both Schools have learned to manage conflict in a positive manner after the intervention.

It is noteworthy that both ethnic groups (Sinhalese and Tamil) of Sri Lankan primary school students were able to successfully apply Olympism values in conflict resolution situations, indicating how accepted Olympism values can be quite possibly interpreted across the multi cultures of the society in mediation of conflict. There are a number of potential reasons that address this result. First, the Olympism values that students learned during the intervention were merely associated with Sri Lankan values and were not unfamiliar to Sri Lankan students. This finding supports Tavares's (2006) argument that Olympism is a reconciliation between romantic values (the notions of honour, duty, self-surpassing, fair-play, moral excellence and a feeling of belonging) and values from illuminism (individualism, universalism, belief in the transforming power of education and the value of competition). This finding also supports Parry's (2003) argument that Olympism is a universal concept but the interpretation of the concept is culturally relative, since the ideas contained within Olympism generate their own meanings, language and practice. This finding acknowledges Segrave's (2004) argument that many people do not know that the Olympic Movement is attached to universalist principles of peace, reconciliation, nobility and the betterment of the human lot.

Second, the CR and OE integrated model curriculum, sporting activities that were used and the effective teaching may have made an impact on both Sinhalese and Tamil students' proficiency of understanding and practice of Olympism values. This is clearly one of the major positive outcomes of this study. Interestingly, students of both schools who represented two different ethnicities accepted integrated sporting activities and theoretical aspects (humanism) associated with Olympism values as a useful tool for integrating people to reduce conflicts. This finding provides insights into the importance of combining theoretical instructions and practical approaches in changing students' conflict resolution learning through concepts of Olympism. An intentional change becomes possible when a person develops knowledge to understand what are needed to be changed and what practices are going to be changed. Therefore, the integrated Olympism and conflict resolution curriculum model provided opportunities for students to integrate theoretical knowledge and practical elements of conflict resolution by involving in experiential learning. This learning approach led students of two ethnic groups to pay attention to their own experiences in conflict resolution while involving in sporting activities. Students' competencies on theoretical reflections have also helped them change their self-understandings. Therefore, a well balanced 
theoretical and practice based integrated Olympism and conflict resolution model would be able to enhance students' conflict resolution competencies.

\section{Personal competencies transformed to the social competencies of CR through four learning stages}

As learning is complicated in a post-conflict society, it is important to find out how students' learning is traumatized by war. I selected 'Transformative learning theory' (Mezirow, 1996) to support my findings. This emerged because traumatize situation in Sri Lanka has changed peoples' lives. When learners begin to re-evaluate their lives in response to life experiences (may be life changing events like a death of somebody, manmade disaster) and remaking themselves is the 'transformative learning' (Mezirow, 1996). Mezirow (1996) developed this theory based on two concepts; meaning schemes and meaning perspectives. Common themes of transformative learning theory are disorienting dilemmas (a mismatch with knowledge, beliefs and values), critical reflection (recognition that one's discontent and the process of transformation are shared) and rational discourse (explorations of options for new roles, relationships and actions) (Mezirow, 1996, p. 17).

According to the pre-test results it was identified that at the beginning of the intervention students had mixed (positive and negative) ideas and free exploration about conflicts. It was also found that students' competencies in CR were generally associated with their body. For instance, pre-test results revealed that students' conflict resolution knowledge, attitudes and skills were associated with their self-preservation. This suggests that before the intervention most of the students had defined conflicts from pessimistic personal views, or opinions on stereotypes. Students explored their CR ideas based on the image of their body and also in consideration of their physical ability when dealing with conflict. This was probably because students tended to relate conflict resolution with multifarious ideas including stereotypes and misunderstandings as a result of the violent experiences in their society. Pretest results demonstrated that students were confused and unfamiliar with selecting appropriate conflict resolution strategies according to the ongoing situation. This stage, discovered by Mezirow (1996) is described as the 'disorientate stage' of transformative learning.

Subsequently, when the CR and OE integrated intervention was implemented students gradually received guided explorations from their teachers about their body structure and physical wellbeing (physical literacy), ways of living (social literacy), critical reflection (critical literacy) and finally, conflict resolution (CR) literacy. Mezirow (1996) described this learning stage as 'perceptive stage'. At this learning stage students were guided to note down and understand different views of conflicts that were not noticed most of the 
time. For instance the use of the term 'body' helped students to understand not only who I am (my physical ability), and why I need to keep up my physical and mental fitness, but also to think of how others maintain their fitness (other's physical abilities), how a person can help other's wellbeing and the importance of balancing physical and mental fitness in society. This is supported by Coubertin's (1936) view that:

Sport for the harmony of the human machine for the smooth equilibrium of mind and body, for the joy of feeling oneself more intensely (Coubertin, 1936, line, 6)

It seems that Coubertin expected to build up a better society by endorsing the 'balance development' concept for body and mind. The findings of this study revealed that Coubertin's above mentioned views can be applied to encourage better living among the younger generation.

The use of 'social literacy' in the OE and CR integrated intervention helped students to understand ways in which their 'bodies' respond to the diverse society. Throughout the process of $\mathrm{CR}$ and $\mathrm{OE}$ integrated intervention experimental group students learned that harmony is one of the most important concepts required to live cooperatively and peacefully in society. These students also gained knowledge by understanding and applying social cohesion to their living conditions and agreed those were the best ways for better living.

Critical literacy provided insights into experimental group students rethinking about the cause and effect of conflict during the intervention. Post-test results revealed that experimental group students were able to critically reflect on their involvement in conflicts, and the causes and consequences. The teachinglearning process of the $\mathrm{CR}$ and $\mathrm{OE}$ integrated model within the $\mathrm{CR}$ and $\mathrm{OE}$ curriculum allowed students to rethink their previous abilities by creating and developing new critical thinking for complex situations. Conflict resolution literacy granted the effective CR strategies, such as the knowledge of how to avoid aggressiveness, the usefulness of cooperativeness for conflict resolution, the importance of positive attitudes and the knowledge of CR, and how to reduce negative attitudes to conflicts. This learning stage is regarded as the 'perceptive stage' of learning conflict resolution. Mezirow (1996) describes this learning segment as 'self-exam' (critical reflection) of transformative learning.

During the intervention process, the experimental group students from both schools had the opportunity to 'interact' and to 'explore' the relationship between their own and others' bodies. During this time experimental group students reflected what went wrong and corrected themselves. Through the 'reflexivity' students learned how to change the ways of thinking (gradually 
conversed) of their body images and developed competencies in thinking of other people (critical reflexivity).

Through practical involvement, discussions and interpretations of critical thinking, students became aware of a 'way of living' (social literacy) that others in the world recognised and understood as the reality for them of how to live. Thus students were able to transform their thinking of ways of living from collectivistic to individualistic ideas. Students also strongly recognised the need for realisation of their ways of living and learned how to reconstruct their ways of living according to their real life conditions.

Post-test results showed that experimental group students learned how to change situations through critical thinking and this joy in effort consolidated these students' experiences and reconstructed knowledge. Perhaps this is because effectiveness of the activities used during the intervention. This learning stage is referred to as the acquisitive stage of CR learning. Mezirow (1996) introduced this learning segment as 'rational discourse' of transformative learning.

Overall, it was considered that the stages of Mezirow's (1996) transformative learning contributed to the effectiveness in improving experimental group student's CR competencies in both schools.

\section{Conclusions}

This study aimed to investigate whether a comprehensive approach of teaching and learning process in Olympism education can enhance conflict resolution skills in Sri Lankan primary school students. Considering the effects of the intervention and the analyses performed in this study, the most notable confirmatory finding was that conflict resolution and Olympism education integrated curriculum intervention was useful, applicable and significantly improved experimental group students' conflict resolution competencies regardless of their ethnicity. There were two patterns of growth in experimental group student's conflict resolution competencies. First the increasing rates of growth for outcomes such as positive attitudes of CR, knowledge of CR and cooperativeness. Second, the decreasing rates of growth for outcomes such as negative attitudes of conflict resolution and assertiveness. This study's intervention demonstrated significant gains in young children's ability to learn to resolve their conflicts when they were exposed to physical education lessons through the combined theoretical knowledge and practicing sporting activities with teaching Olympism values. Findings of the study supported the stages of Mezirow's Transformative Learning Theory. 


\section{References}

Bailin, S., Case, R., Coombs, J. R., \& Daniels, L.B. (1999). Conceptualizing Critical Thinking. Journal of Curriculum Studies, 31(3), 285-302. http:// dx.doi.org/10.1080/002202799183133

Bandarage, A. (2008). The Separatist Conflict in Sri Lanka: Terrorism, Ethnicity, Political economy. London: Routledge Publishers.

Bilgin, A. (2008). The impact of conflict resolution training on elementary school children. Elementary Education Online, (7), 541-556.

Binder, D. L. (2001). Olympism revisited as context for global education: Implications for physical education. Quest, 53(1), 14-34. http://dx.doi.or g/10.1080/00336297.2001.10491728

Breunlin D. C., Cimmarusti R. A., Bryant-Edwards, T. L., \& Hetherington, J. S. (2002). Conflict Resolution Training as an Alternative to Suspension for Violent Behavior. The Journal of Educational Research, (95), 349357. http://dx.doi.org/10.1080/00220670209596609

Bronikowski, M. (2006). Achievements in teaching Olympism in Polish schools. Research Yearbook, MEDSPORTPRESS, 12(2), 184-189.

Coubertin, P. (1936). In N. Muller (2000). (Eds.). Pierre de Coubertin (18631937) Olympism: Selected writings. Lausanne: International Olympic Committee.

Culpan, I. (2001). The pedagogy of neo-Olympism in a national physical education curriculum: The Greek connection, (pp. 442-449). Proceedings of the International Olympic Academy Special Session, Olympia: Greece.

Culpan, I. \& Moon, C. (2009). Defining Olympism education. Unpublished work. Christchurch: Olympic Studies Centre, University of Canterbury.

Culpan, I. \& Wigmore, S. (2010). The delivery of Olympism education within a physical education context drawing on critical pedagogy. International Journal of Sport and Health Science, (8), 67-76. http:// dx.doi.org/10.5432/ijshs.20090028

Diem, L. (1986). A Pedagogical Challenge. Olympic Review (227), 4-5. Retrieved on May 4, 2010, from http://www.la84foundation.org/ OlympicInformationCenter/OlympicReview/1986/ore136/ore136zc.pdf 
Edleson, J. E. (1981). Teaching children to resolve conflicts: A group approach. Social work, (26), p. 488.

Encarnacion, T., McCartney, C., \& Rosas, C. (1990). In Ramsbotham, O., Woodhouse, T., \& Miall, H. (2005). (2nd Ed). Contemporary Conflict Resolution: The prevention, management and transformation of deadly conflicts. Cambridge: Polity Press.

Garbarino, J., Dubrow, N., Kostelny, K., \& Pardo, C. (1992). Children in danger: Coping with the consequences of community violence. San Francisco: Jossey Bass publishers.

Garca, M. (2001). The Impact of War on Children. London: Hurst and Company for UNICEF \& UNIFEM.

Ha, S. A. (2004). The effects of different teaching approaches of a valuebased Olympic education programme on the moral development of Hong Kong children. 2004 pre- Olympic Congress proceedings, Thessaloniki, Greece. Retrieved on June 6, 2009, from http://cev.org.br/eventos/ athens-2004-pre-olympic-congress/trabalhos/pdf.

Hart, J. (2004). Children's Participation in Humanitarian Crises: Learning from zones of armed conflict. Synthesis report prepared for the Canadian International Development Agency. Oxford: Refugee Studies Centre Publication.

Heydenberk, R., \& Heydenberk, W. (2005). Increasing meta-cognitive competence through conflict resolution. Education and Urban Society, 37(4), 431-452. http://dx.doi.org/10.1177/0013124505277747

Honig, A. S. (1982). Prosocial development in children [Research in review]. Young Children, 37(5), 51- 62.

Huesmann, L. (1986). Psychological Processes Promoting the Relation between Exposure to Media Violence and Aggressive Behavior by the viewer. Journal of Social Issues, (42), 125-139. http://dx.doi. org/10.1111/j.1540-4560.1986.tb00246.x

International Olympic Committee (IOC), (2010). The Olympic Charter. Lausanne: International Olympic Committee.

Johnson, D. W., \& Johnson, R. (2005). Teaching students to be Peacemakers. Edina, Minnesota: Interaction Book Company. 
Kabitsis, C., Harahouson, Y., Arvaniti, N., Mountakis, K. (2002). Implementation of Olympic culture in the school curriculum in Greece. Retrieved on June 26, 2009, fromhttp://www.find26.6.2009articles. com/p/articles/mihb4322/is_4_59/ai_n28964588/pg_3/?tag=conten.

Kamberidou, I. (2008). Promoting a culture of peacemaking: Peace games and peace education. International Journal of Physical education (IJPE), (4) (November), 176-182.

Kidd, B., \& MacDonnell, M. (2007). Literature reviews on Sport for Development and Peace: peace, sport and development. (SDP IWG, Ed.) Retrieved December 1, 2009, from http://iwg.sportanddev.org/data/ htmleditor/file/Lit.\%20Reviews/literature\%20review\%20SDP.pdf

Kidd, B. (2008). A New Social Movement: Sport for Development and Peace. Sport in society, (11), 370-380. http://dx.doi. org/10.1080/17430430802019268

Kincheloe, J. L. (2005). Critical Constructivism. New York : Peterlang primers Publishers.

Lassoued, B. (1997). The Educational aspect of the Olympic ideal. Olympic Review. June/July 1997 XXVI, 11-13. Retrieved on April 6, 2009, from http:/www.la84foundation.org/OlympicInformationCenter/ OlympicReview/1997/oreXXVI15/oreXXVI15o.pdf.

Lederach, J. P. (1997). Building Peace: Sustainable Reconciliation in Divided Societies. Washington, DC: United States Institute of Peace Press.

Lopes-Cardozo, M. (2009). Sri Lanka: in peace or in pieces? A Critical approach to Peace Education in Sri Lanka. Peace Education, Sri Lanka, Working paper 4. Retrieved on December 18, 2010, from http://www. educationanddevelopment.wordpress.com/publications.

Mezirow, J. (1996). Contemporary paradigms of learning. Adult Education Quarterly, (46), 158-172. http://dx.doi. org/10.1177/074171369604600303

Ministry of Education, Sri Lanka (MOESL). (2002). Annual Report 2002, Colombo: Government Press.

Morton, I. (1991). Conflict Resolution Programs in Schools. ERIC/CUE Digest (74). New York: ERIC Clearinghouse on Urban Education Publication. 
Muller, N. (2004). Olympic Education: University Lecturers on the Olympics. Centre d' Estudis Olympics, Universitat Autonoma de Barcelona (2004), 7. Retrieved on december 17, 2009, from http://www.olympicstudies. uab.es/lec/pdf/muller.pdf.

Naul, R. (2008). Olympic Education. Oxford: Meyer \& Mayer Verlag Publishers.

Nicolai, S., \& Triplehern, C. (2003). The Role of Education in protecting children in conflict. London: Humanitarian Practice Net Work (HPN) Publishers.

Norman, M. (2009). Playing for peace? The relationship of sport to peace building in divided societies. Unpublished MA thesis. Toronto: Simon Fraser University. Retrieved on May 4, 2011, from http://www.summit. sfu.ca/system/files/iritems1/9726/ETD4652.pdf.

Parry, J. (2003). Olympic Education in Practice. A paper prepared for the Centre d'Estudis Olimpics, Barcelona.

Patsantaras, N. (2008). Olympic message: Olympic ideology and Olympic social reality. Sport Management International Journal 4 (1), 45-54.

Ramsbotham, O., Woodhouse, T., \& Miall, H. (2005). (2nd Ed). Contemporary Conflict Resolution: The prevention, management and transformation of deadly conflicts. Cambridge: Polity Press.

Segrave, J. (2004). The Olympic Games 393 AD-1896 AD: The genealogy of an idea in literature, music and dance. Olympika: The International Journal of Olympic Studies, 13, 53-74.

Solomon, D. (2002) The Nature of Peace Education: Not all Programs are Created Equal. In G. Soloman, \& B. Nevo, (Eds). Peace Education: The Concept, Principles and Practices around the World, pp. 3-15. Mahwah, New Jersey: Erlbaum Publishers.

Tavares, O. (2006). Olympic values in the 21st century: between continuity and change. Barcelona: Center for Olympic Studies. Retrieved on July 5, 2010, from http:// www. Olympicstudies.uab.es/lec/pdf.

Taylor, P. (1998). Constructivism: value added. In: B. Fraser \& K. Tobin (Eds), The International handbook of science education, Dordrecht, The Netherlands: Kluwer Academic. http://dx.doi.org/10.1007/978-94-0114940-2_65 
United Nations. (2006). United Nations Development Programme, Youth and Violent Conflict: Society and development in Crisis? p. 26. New York: UNDP. Retrieved on July 2, 2009, from http://www.un.org/ youthandviolentconflicts 2006 .

UNICEF. (2001). Fact Sheet: Child Soldiers. Retrieved on June 5, 2009, from http://www.unicef.org/emerg/files/childsoldiers.pdf. 